IIIIIIIIIIIIIIIIIIIIIIIIIIIIIIIIIIII

Original Article

IIIIIIIIIIIIIIIIIIIIIIIIIIIIIIIIIII

\title{
Effects of environmental factors on the herbicidal activity and phytotoxicity of ipfencarbazone
}

\author{
Tatsuya Kasahara, ${ }^{1, *}$ Takashi Takeuchi, ${ }^{1}$ Kohei Koyama ${ }^{2}$ and Seiichi Kuzuma ${ }^{2}$ \\ ${ }^{1}$ Hokko Chemical Industry Co., Ltd., 1-5-4 Nihonbashi Honcho, Chuo-ku, Tokyo 103-8341, Japan \\ ${ }^{2}$ Central Research Laboratories, Hokko Chemical Industry Co., Ltd., 2165 Toda, Atsugi-shi, Kanagawa 243-0023, Japan
}

(Received April 8, 2018; Accepted August 15, 2018)

\begin{abstract}
Ipfencarbazone exhibits excellent herbicidal activity against Echinochloa spp. and is safe for transplanted rice at a dose of $250 \mathrm{~g}$ a.i./ha. However, the effect of various environmental factors on its activity has not been verified. The present study evaluated the factors affecting the herbicidal activity of ipfencarbazone against Echinochloa spp. and its phytotoxicity to transplanted rice. The herbicidal activity and phytotoxicity of ipfencarbazone were barely affected by temperature, soil texture, water leakage, or flooding water depth. When an overflow was conducted artificially $6 \mathrm{hr}$ after application, the herbicidal activity was stable. Furthermore, ipfencarbazone completely inhibited the emergence of Echinochloa spp. for 56 days regardless of the soil texture, water leakage and overflow conditions. When the period between application and reflooding was within $24 \mathrm{hr}$ of herbicide application, the phytotoxicity of ipfencarbazone on transplanted rice was slight. These results suggest that ipfencarbazone shows stable efficacy in practical use. () Pesticide Science Society of Japan

Keywords: ipfencarbazone, herbicidal activity, phytotoxicity, overflow, simultaneous application with transplanting.
\end{abstract}

\section{Introduction}

Ipfencarbazone [1-(2,4-dichlorophenyl)-2',4'-difluoro-1,5dihydro- $N$-isopropyl-5-oxo-4H-1,2,4-triazole-4-carboxanilide] is a novel herbicide developed by Hokko Chemical Industry Co., Ltd. Ipfencarbazone has been reported to exhibit excellent herbicidal activity against annual weeds such as Echinochloa spp., Lindernia spp. and Cyperus difformis at a dose of $250 \mathrm{~g}$ a.i./ha (practical dose). ${ }^{1)}$ Especially when it was applied before the emergence of weeds, it controlled the growth of Echinochloa spp. for a long time. Furthermore, it is safe for transplanted rice seedlings. ${ }^{1,2)}$

Generally, the herbicidal activity and selectivity of herbicides on weeds and crops are known to be affected by various environmental factors, such as temperature, water leakage, soil texture and water overflow. ${ }^{3-11)}$ However, the effects of these environmental factors on the herbicidal activity and phytotoxicity of ipfencarbazone have not been verified.

Recently, the application of herbicides simultaneously with transplanting has become a popular labor-saving technique in rice cultivation. This application method omits additional weed control and enables uniform application of the herbicide. On the other hand, simultaneous herbicide application and trans-

\footnotetext{
* To whom correspondence should be addressed.

E-mail: Kasahara-t@hokkochem.co.jp

Published online September 28, 2018

(C) Pesticide Science Society of Japan
}

planting necessitates the control of weed growth for a long time. Another important aspect to be considered with this method is the period between application and reflooding. Generally, paddy fields are reflooded after rice seedlings are transplanted, and then herbicides are applied. However, during simultaneous application and transplanting, the herbicide is applied under the condition of low flooding water depth. When applied under low flooding water depth conditions, herbicides were absorbed by transplanted rice seedlings at a higher concentration, thus, worsened phytotoxicity was expected. ${ }^{11)}$ If there is a long time lapse between herbicide application and reflooding, since the rice seedlings are likely to absorb a high concentration of herbicide, there is concern that phytotoxicity on rice seedlings will worsen.

The present study evaluated the effects of temperature, soil texture, water leakage, and water overflow on the herbicidal activity of ipfencarbazone against Echinochloa spp. and its safety for transplanted rice seedlings. Furthermore, to evaluate the capability of herbicide application simultaneously with transplanting, we investigated the effect of flooding water depths and the period between herbicide application and reflooding.

\section{Materials and Methods}

\section{Materials}

The herbicidal activity of ipfencarbazone was evaluated using Echinochloa spp., including Echinochloa crus-galli Beauv. var. crus-galli, E. crus-galli Beauv. var. formosensis Ohwi and E. oryzicola Vasing. These seeds were collected in paddy fields located in Atsugi City, Kanagawa, Japan. The phytotoxicity of ipfencar- 
Table 1. Characteristics of tested soils ${ }^{a)}$

\begin{tabular}{|c|c|c|c|c|c|c|c|}
\hline \multirow[b]{2}{*}{ Location } & \multirow[b]{2}{*}{ Soil type } & \multicolumn{4}{|c|}{ Particle size distribution (\%) } & \multirow{2}{*}{$\begin{array}{c}\text { Organic } \\
\text { matter } \\
(\%)\end{array}$} & \multirow{2}{*}{$\begin{array}{c}\mathrm{pH} \\
\left(\mathrm{H}_{2} \mathrm{O}\right)\end{array}$} \\
\hline & & $\begin{array}{c}\text { Coarse } \\
\text { sand }\end{array}$ & $\begin{array}{l}\text { Fine } \\
\text { sand }\end{array}$ & Silt & Clay & & \\
\hline Atsugi & Light clay & 18.9 & 25.7 & 29.4 & 26.0 & 2.57 & 6.8 \\
\hline Kasumigaura & Sandy loam & 1.4 & 82.8 & 8.4 & 7.4 & 2.95 & 5.9 \\
\hline
\end{tabular}

a) The physical characteristics of the tested soils were analyzed by PALYNO SURVEY Co., Ltd., Japan.

bazone was evaluated using rice plants (Oryza sativa L. 'Nipponbare'). The test compound, the technical grade of ipfencarbazone, was diluted in $10 \%$ acetone solution containing $1 \%$ nonionic surfactant. Unless stated otherwise, each experiment was carried out in triplicate in a glass greenhouse (natural light, minimum/maximum temperature: $13.6 / 32.1^{\circ} \mathrm{C}$ ).

\section{Effect of temperature on herbicidal activity and phytotoxicity}

A Wagner pot (1/5000a) was filled with light clay (characteristics of the tested soil are presented in Table 1). The soil in the pot was puddled after flooding. The seeds of Echinochloa spp. were sown on the soil surface or rice seedlings at the 2.1 leaf stage were transplanted at a depth of $2 \mathrm{~cm}$. After sowing or transplanting, the pots were flooded with water to a depth of $3 \mathrm{~cm}$. The pots were placed in growth chambers at $30 / 25^{\circ} \mathrm{C}, 25 / 20^{\circ} \mathrm{C}$, or $20 / 15^{\circ} \mathrm{C}$ (day/night cycle, $14 / 10 \mathrm{hr}$ ).

When the Echinochloa spp. grew to a 3.0 leaf stage or after the rice seedlings were transplanted, $250 \mathrm{~g}$ a.i./ha of ipfencarbazone was applied on the water. The dry weight of shoots was measured 30 days after application. During the experiment, the flooding water depth was maintained at $3 \mathrm{~cm}$ without water leakage.

\section{Effect of soil texture on herbicidal activity and phytotoxicity}

Light clay or sandy loam was used (characteristics of the tested soil are presented in Table 1$)$. Wagner pots (1/5000 a) were filled with either light clay or sandy loam. The soil in the pots was puddled after flooding. The sowing of Echinochloa spp., transplanting of rice seedlings and herbicide application were carried out as described in section 2 . The dry weight of shoots was measured 28 days after herbicide application.

The residual activity of ipfencarbazone was evaluated as follows. After filling a Wagner pot $(1 / 5000 \mathrm{a})$ with either light clay or sandy loam, the soil was puddled after flooding. Subsequently, 4-5 seeds of germinated Echinochloa spp. were sown on the soil surface, and the pots were flooded with water to a depth of $3 \mathrm{~cm}$. On the next day after puddling, an ipfencarbazone solution was applied to the water surface at a dose of $250 \mathrm{~g}$ a.i./ha. At an interval of 7 days, 4-5 seeds of germinated Echinochloa spp. were sown onto the surface of the soil after the application of ipfencarbazone, and the degree of growth inhibition (herbicidal activity) was examined by a visual rating ( $0 \%$ (no weed control) to $100 \%$ (complete inhibition)) 28 days after sowing. During the experiment, the flooding water depth was maintained at $3 \mathrm{~cm}$ without water leakage.

4. Effect of water leakage on herbicidal activity and phytotoxicity A Wagner pot (1/5000a) was filled with light clay. The puddling of soil, seeding of weeds, transplanting of rice seedlings and herbicide application were carried out as described in section 2. Water leakage was carried out at a rate of $2 \mathrm{~cm} /$ day for 5 days from the day after herbicide application. The dry weight of shoots was measured 28 days after herbicide application.

Except for the water leakage condition, the residual activity of the herbicide was evaluated under conditions similar to those described in section 3. Water leakage was carried out at a rate of 1 or $2 \mathrm{~cm} /$ day for 5 days from the day after herbicide application. During the experiment, the flooding water depth was maintained at $3 \mathrm{~cm}$.

\section{Effect of paddy water exchange (overflow) on herbicidal activ-} ity

To assess the effect of overflow due to sudden heavy rainfall, we evaluated the herbicidal activity of ipfencarbazone under an overflow condition. A Wagner pot (1/5000a) was filled with light clay. The puddling of soil, seeding of weeds and herbicide application were carried out as described in section 2. Overflow was carried out according to the method described by Morita et al. ${ }^{12)}$ Paddy water equivalent to $100 \mathrm{~mm}$ of rainfall was exchanged for tap water 3,6 , and $24 \mathrm{hr}$ after application. The dry weight of shoots was measured 31 days after application.

Except for overflow conditions, the residual activity of herbicide was evaluated under conditions similar to those described in section 3. According to the method of Morita et al., ${ }^{12)}$ artificial overflow was carried out as follows. Paddy water equivalent to 50 or $100 \mathrm{~mm}$ of rainfall was exchanged for tap water $6 \mathrm{hr}$ after application. During the experiment, the flooding water depth was maintained at $3 \mathrm{~cm}$ without water leakage.

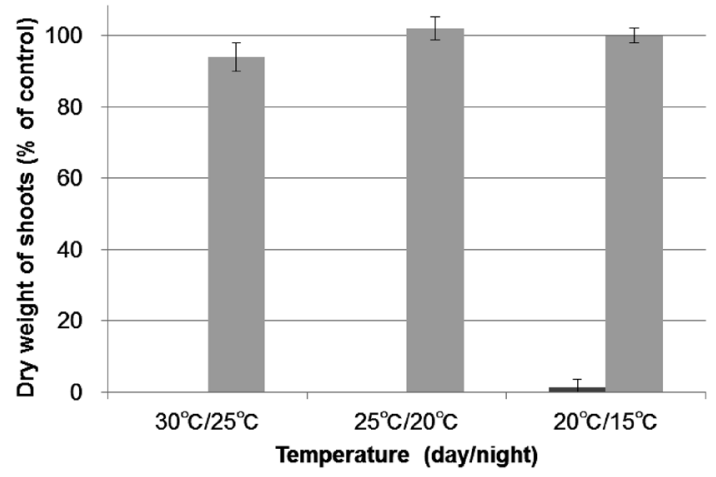

Fig. 1. Effects of temperature on the herbicidal activity of ipfencarbazone against Echinochloa spp. ( $\square$ ) at the 3.0 leaf stage and its phytotoxicity to rice seedlings $(\square)$ just after transplanting at a dose of $250 \mathrm{~g}$ a.i./ha. Dry weight was measured 30 days after application. Vertical bars represent \pm standard deviation (SD). 


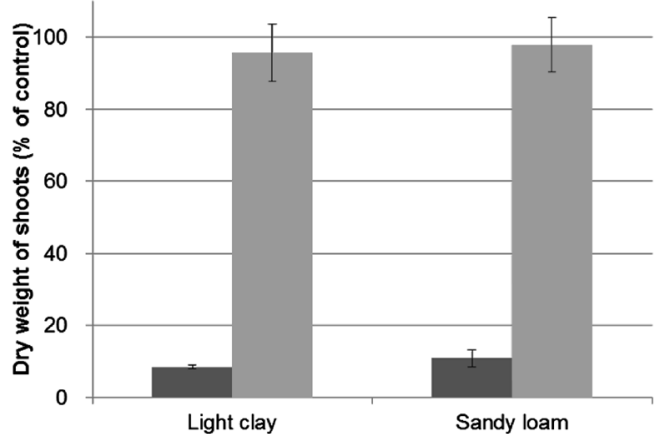

Fig. 2. Effects of soil texture on the herbicidal activity of ipfencarbazone against Echinochloa spp. ( $\square$ ) at the 3.0 leaf stage and its phytotoxicity to transplanted rice seedlings ( $\square$ ) just after transplanting at a dose of $250 \mathrm{~g}$ a.i./ha. Dry weight was measured 28 days after application. Vertical bars represent $\pm \mathrm{SD}$.

6. Effect of flooding water depth on herbicidal activity and phytotoxicity

A Wagner pot (1/5000a) was filled with light clay. The puddling of soil, seeding of weeds, transplanting of rice seedlings and herbicide application were carried out as described in section 2 . The flooding water depth during the application was adjusted to 1 , 3 , or $8 \mathrm{~cm}$. The dry weight of shoots was measured 30 days after application. During the experiment, the flooding water depth was maintained during application without water leakage.

7. Effect of the period between herbicide application and reflooding on phytotoxicity

A Wagner pot (1/5000a) was filled with light clay. The puddling of soil and transplanting of rice seedlings were carried out as described in section 2. After the transplanting of rice seedlings, the paddy water was removed and ipfencarbazone was applied to the soil surface at a rate of $250 \mathrm{~g}$ a.i./ha approximately $2 \mathrm{~cm}$ from the rice seedlings. At 3, 6 or $24 \mathrm{hr}$ after application, the pots were reflooded to a depth of $3 \mathrm{~cm}$. The dry weight of shoots

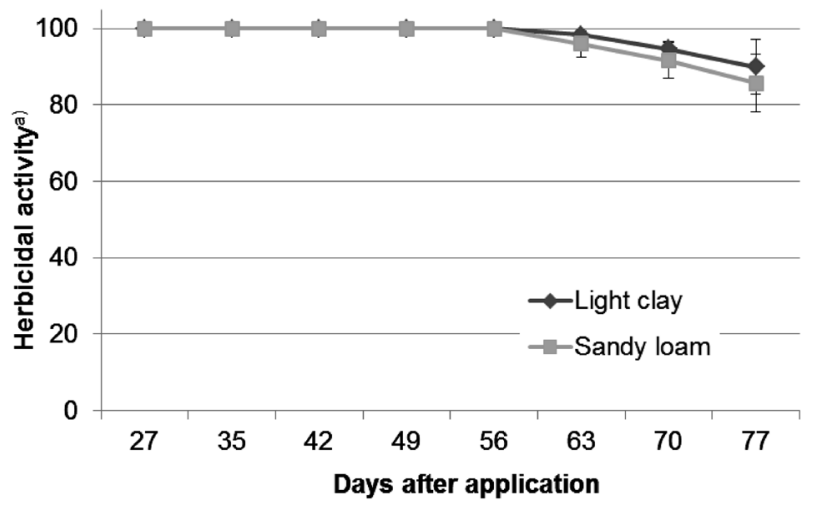

Fig. 3. Effect of soil texture on the residual activity of ipfencarbazone against pre-emergent Echinochloa spp. at a dose of $250 \mathrm{~g}$ a.i./ha. Herbicidal activity was evaluated visually 28 days after sowing. Vertical bars represent \pm SD. ${ }^{a)}$ Rating scale, $0 \%$ (no weed control)-100\% (complete inhibition).

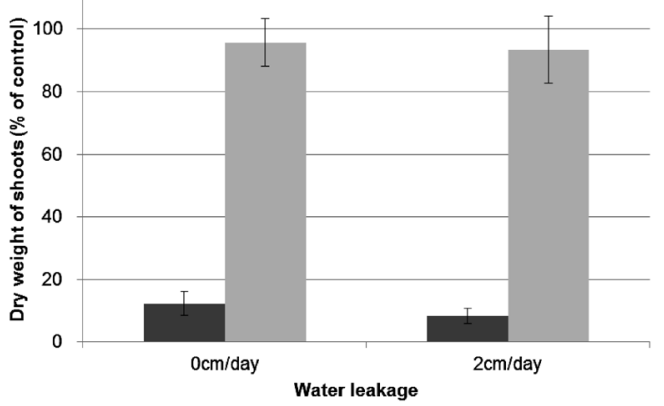

Fig. 4. Effects of water leakage on the herbicidal activity of ipfencarbazone against Echinochloa spp. (অ) at the 3.0 leaf stage and its phytotoxicity against rice seedlings ( $\square$ ) just after transplanting at a dose of $250 \mathrm{~g}$ a.i./ha. Dry weight was measured 28 days after application. Vertical bars represent \pm SD.

was measured 30 days after application. During the experiment, the flooding water depth was maintained at $3 \mathrm{~cm}$ without water leakage.

\section{Statistical analysis}

Statistical significance was determined using the SPSS Statistics software version 24.0 (IBM Japan Corp., Nihonbashi, Tokyo, Japan). Tukey's test was conducted and the difference was considered significant at $p<0.05$.

\section{Results}

\section{Effect of temperature on herbicidal activity and phytotoxicity} Ipfencarbazone exhibited excellent herbicidal activity against Echinochloa spp. at the 3.0 leaf stage under all temperature conditions. In particular, under the $30 / 25^{\circ} \mathrm{C}$ and $25 / 20^{\circ} \mathrm{C}$ conditions, ipfencarbazone completely killed Echinochloa spp. at the 3.0 leaf stage and there was no significant difference in herbicidal activity among the temperature conditions. Similarly, the dry weight of transplanted rice decreased marginally under all temperature conditions (Fig. 1).

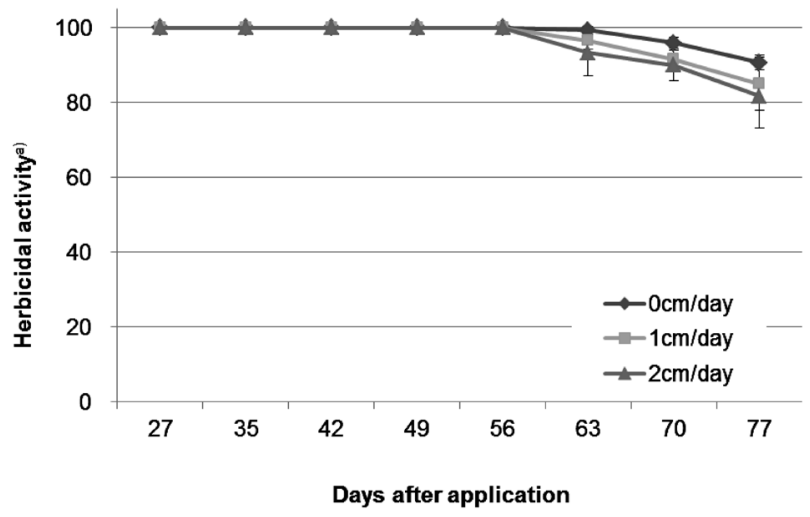

Fig. 5. Effect of water leakage on the residual activity of ipfencarbazone against pre-emergent Echinochloa spp. at a dose of $250 \mathrm{~g}$ a.i./ha. Herbicidal activity was evaluated visually 28 days after sowing. Vertical bars represent \pm SD. ${ }^{a}$ ) Rating scale, 0\% (no weed control) to 100\% (complete inhibition). 


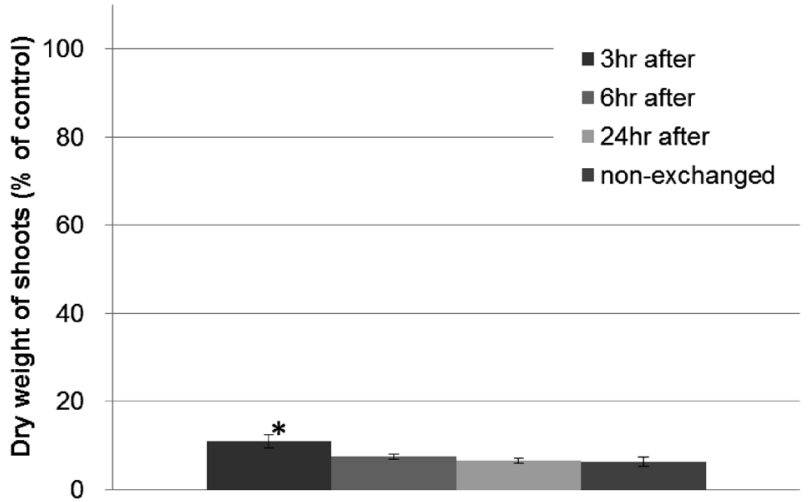

Fig. 6. Effect of exchanged paddy water on the herbicidal activity of ipfencarbazone against Echinochloa spp. at the 3.0 leaf stage at a dose of $250 \mathrm{~g}$ a.i./ha. Dry weight was measured 31 days after application. Vertical bars represent $\pm \mathrm{SD}$. The asterisk $(*)$ indicates that a significant difference was observed among the conditions with no exchanging of paddy water.

\section{Effect of soil texture on herbicidal activity and phytotoxicity} Ipfencarbazone exhibited high herbicidal activity against Echinochloa spp. at the 3.0 leaf stage in light clay and sandy loam. The dry weight of transplanted rice decreased marginally in both soils and there was no significant difference in phytotoxicity between the two soils (Fig. 2). Additionally, ipfencarbazone completely inhibited the emergence of Echinochloa spp. for 56 days after application in both soils. From 63 days after application, the residual activity of ipfencarbazone against Echinochloa spp. decreased, and the rate of decrease in both soils was similar (Fig. 3).

\section{Effect of water leakage on herbicidal activity and phytotoxicity} Ipfencarbazone exhibited excellent herbicidal activity against Echinochloa spp. at the 3.0 leaf stage regardless of water leakage. The dry weight of transplanted rice decreased marginally regardless of water leakage (Fig. 4). Furthermore, ipfencarbazone completely inhibited the emergence of Echinochloa spp. for 56

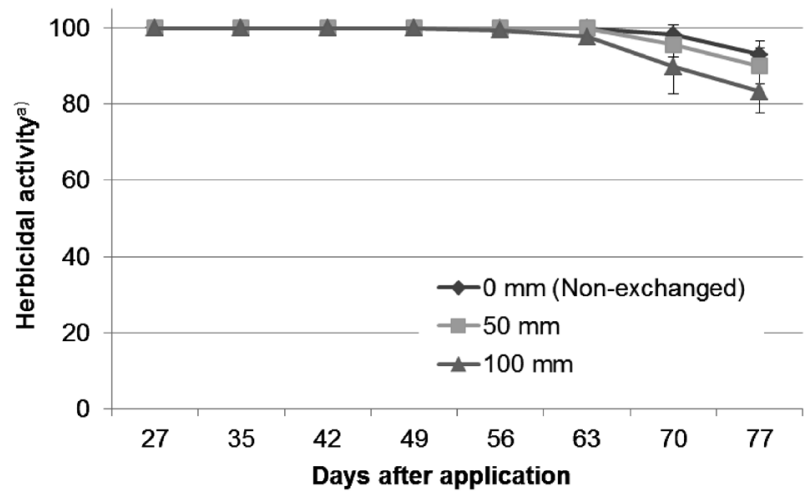

Fig. 7. Effect of exchanged paddy water on the residual activity of ipfencarbazone against pre-emergent Echinochloa spp. at a dose of $250 \mathrm{~g}$ a.i./ha. Herbicidal activity was evaluated visually 28 days after sowing. Vertical bars represent \pm SD. ${ }^{a)}$ Rating scale, $0 \%$ (no weed control) to $100 \%$ (complete inhibition).

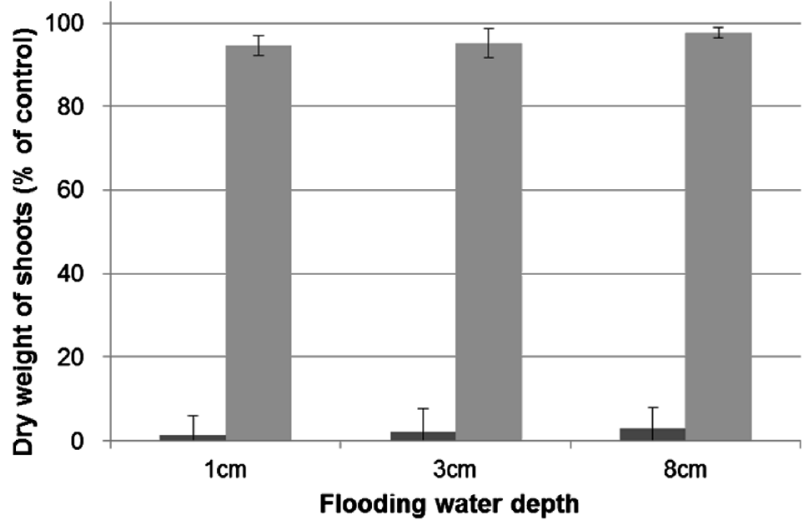

Fig. 8. Effect of flooding water depth on the herbicidal activity of ipfencarbazone against Echinochloa spp. ( $\square$ ) at the 3.0 leaf stage and its phytotoxicity against rice seedlings ( $\square$ ) just after transplanting at a dose of $250 \mathrm{~g}$ a.i./ha. Dry weight was measured 30 days after application. Vertical bars represent $\pm \mathrm{SD}$.

days after application (Fig. 5). With an increase in the amount of water leakage, the residual activity tended to decrease from 63 days after application. However, there was no significant difference in residual activity among the water leakage conditions.

\section{Effect of paddy water exchange (overflow) on herbicidal activ- ity}

When the paddy water was exchanged $3 \mathrm{hr}$ after application, the dry weight of Echinochloa spp. at the 3.0 leaf stage increased in comparison with the condition in which paddy water was not exchanged. However, when the paddy water was exchanged 6 or $24 \mathrm{hr}$ after application, ipfencarbazone exhibited excellent herbicidal activity against Echinochloa spp. (Fig. 6). Ipfencarbazone completely inhibited the emergence of Echinochloa spp. for 56 days after application regardless of the exchange of paddy water. With an increase in the amount of exchanged paddy water, the residual activity tended to decrease from 63 days after application (Fig. 7). However, there was no significant difference in the

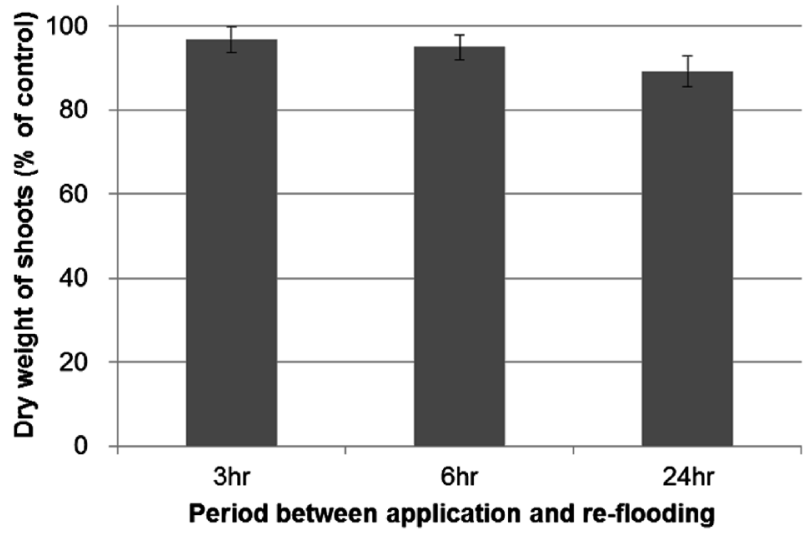

Fig. 9. Effect of the period from herbicide application to reflooding on the phytotoxicity of ipfencarbazone against rice seedlings just after transplanting at a dose of $250 \mathrm{~g}$ a.i./ha. Dry weight was measured 30 days after application. Vertical bars represent $\pm \mathrm{SD}$. 
residual activity among the amounts of paddy water exchanged.

\section{Effect of flooding water depth on herbicidal activity and phy- totoxicity}

Ipfencarbazone exhibited excellent herbicidal activity against Echinochloa spp. at the 3.0 leaf stage under all flooding water depth conditions. The dry weight of transplanted rice decreased marginally under all flooding water depth conditions. There was no significant difference among the flooding water depth conditions (Fig. 8).

\section{Effect of the period between herbicide application and reflood- ing on phytotoxicity}

As the period between application and reflooding was prolonged, the dry weight of rice seedlings decreased. However, even when the period between application and reflooding was $24 \mathrm{hr}$, the decrease in dry weight was only $7.6 \%$. Furthermore, there was no significant difference among different periods between application and reflooding (Fig. 9).

\section{Discussion}

The present study evaluated the effects of various environmental factors on the herbicidal activity on Echinochloa spp. and the phytotoxicity of ipfencarbazone. The results revealed that the effect of temperature on the activity of ipfencarbazone was negligible (Fig. 1). It has been reported that the phytotoxicity of several herbicides worsens due to the increased absorption of herbicides with an increase in temperature. ${ }^{8,13)}$ It has been confirmed that soil strongly adsorbs ipfencarbazone and forms a layer of ipfencarbazone on the surface. ${ }^{1)}$ It is estimated that plants absorb ipfencarbazone from the basal part of the leaf sheath. ${ }^{14)}$ As the basal part of the leaf sheath on transplanted rice seedlings is normally located below the herbicide layer, it was expected that the transplanted rice would rarely absorb ipfencarbazone regardless of the temperature condition. Therefore, it was inferred that ipfencarbazone did not cause worsening of phytotoxicity to rice seedlings by temperature.

In this study, the soil texture and water leakage did not significantly affect the herbicidal activity or phytotoxicity of ipfencarbazone (Figs. 2-5). The soil texture and water leakage were shown to have an effect on the downward migration of herbicides. ${ }^{15)}$ When the adsorption ability of soil for herbicides is low and/or water leakage is high, the downward migration of herbicides is expected to vary and, consequently, affect the absorption of herbicides by plants. ${ }^{5,6}$ Echinochloa spp. form the basal part of the leaf sheath near the soil surface after germination. ${ }^{16)}$ On the other hand, rice seedlings are transplanted to ensure that the basal part of the leaf sheath is located at a depth of $2-4 \mathrm{~cm}$ in the soil. The difference in the location of the main absorption site probably leads to the physical selectivity between Echinochloa spp. and transplanted rice. Regardless of the soil texture and water leakage condition, it has been confirmed that ipfencarbazone hardly moves downward in the soil and forms an herbicide-treated layer on the soil surface. ${ }^{1)}$ In the experiment, it was considered that the physical selectivity between Echinochloa spp. and transplanted rice was probably maintained by the strong herbicide-treated layer on the soil surface.

The herbicidal activity of ipfencarbazone was maintained when the paddy water was exchanged 6 and $24 \mathrm{hr}$ after application (Figs. 6, 7). A recent study suggested that herbicides with low water solubility are more quickly adsorbed by the soil than are herbicides with high water solubility, and the herbicidal activity was hardly affected by overflow. ${ }^{9)}$ The water solubility of ipfencarbazone has been reported to be $0.515 \mathrm{ppm}^{1)}$ As this value is similar to that of other herbicides, which were reported as not affected by overflow, it was presumed that the herbicidal activity of ipfencarbazone was not significantly affected by the exchange of paddy water $6 \mathrm{hr}$ after application. However, in the present study, when paddy water was exchanged $3 \mathrm{hr}$ after application, the dry weight of Echinochloa spp. increased. Therefore, to maximize the herbicidal activity of ipfencarbazone, drainage of paddy water shortly after application should be avoided.

During simultaneous herbicide application and transplanting, the herbicides are applied under conditions of almost no paddy water in the field. If the period between application and reflooding is prolonged, herbicides are expected to insufficiently diffuse from the application points and to exist at a high concentration. Therefore, to examine ipfencarbazone for application simultaneously with transplanting, the effect of flooding water depth was investigated in the present study. The effect of ipfencarbazone on Echinochloa spp. and transplanted rice did not differ significantly at flooding water depths of $1-8 \mathrm{~cm}$ (Fig. 8). Under shallow water depth conditions, regardless of the period between application and reflooding, the dry weight of transplanted rice slightly decreased (Fig. 9). Ogasawara et al. ${ }^{11)}$ reported that the phytotoxicity of specific herbicides against transplanted rice had worsened at the shallow water depth. The result of the present study suggests that the ability of ipfencarbazone was hardly affected by water depth. However, the dry weight of transplanted rice tended to decrease if the period between application and reflooding was prolonged, which suggests that quick reflooding after application is important to prevent damage to rice plants.

To use herbicides in simultaneous application with transplanting, the herbicides require sufficient residual activity to control weeds for a long time. Suzuki et al. ${ }^{17)}$ reported that if weeds are controlled for 40 days after transplanting, the interference of weeds with rice seedlings is negligible regardless of transplanting time. The result of the present study showed that ipfencarbazone inhibited the emergence of Echinochloa spp. for more than 40 days, even with fluctuations in water leakage, soil texture and overflow (Figs. 3, 5, 7). These findings indicate that ipfencarbazone can exhibit sufficient residual activity even when applied during rice transplanting.

The results of the present study reveal that the herbicidal activity and phytotoxicity of ipfencarbazone at a practical dose were hardly affected by the temperature, soil texture, water leakage, overflow, or flooding water depth. Therefore, ipfencarbazone is suitable for application simultaneously with transplant- 
ing. In the practical use of ipfencarbazone, we would like to suggest that application of the herbicide should not be performed when uncontrolled outflow out is expected due to rainfall. Furthermore, the fields should be quickly reflooded when simultaneous application and transplanting are carried out. By being aware of and attentive to the above points, high herbicidal activity against Echinochloa spp. and safety for transplanted rice can be achieved more effectively with ipfencarbazone under various conditions.

\section{Acknowledgements}

The authors thank the staff of the Central Research Laboratory of Hokko Chemical Industry Co., Ltd., who advised and supported the present study, and the advices of Dr. Hiroshi Matsumoto that improved this manuscript.

\section{References}

1) T. Kido, H. Okita, M. Okamura, T. Takeuchi and K. Morita: J. Pestic. Sci. 41, 113-119 (2016).

2) M. Okamura, S. Kondo, Y. Honma, T. Takeuchi, I. Taketomi, T. Kido, H. Okita and K. Morita: Abstr. 33th Annu. Meeting Pestic. Sci. Soc. Jpn., 36, (2008) (in Japanese).

3) M. Kanzaki, K. Toru, H. Oishi and N. Shirakawa: Weed Research Jpn. 46, 169-174 (2001) (in Japanese).
4) K. Noda, K. Ibaragi and K. Ozawa: Weed Research Jpn. 4, 127-131 (1965) (in Japanese).

5) N. Ichizen, T. Takeuchi, H. Omokawa, M. Konnai and T. Takematsu: Weed Research Jpn. 36, 338-342 (1991) (in Japanese).

6) Y. Uno and Y. Kawamura: Weed Research Jpn. 17, 59-64 (1974) (in Japanese).

7) S. Murakami: Weed Research Jpn. 35, 155-163 (1990).

8) A. Mine, N. Hino and M. Ueda: Weed Research Jpn. 17, 64-70 (1974) (in Japanese).

9) N. Ichizen, K. Yoneyama, M. Konnai and T. Takematsu: Weed Research Jpn. 36, 334-337 (1995) (in Japanese).

10) M. Kanzaki, M. Takeuchi and N. Shirakawa: J. Weed Sci. Tech. 46, 25-30 (2001) (in Japanese).

11) M. Ogasawara, K. Ishikawa and M. Konnai: Weed Research Jpn. 35, 102-108 (1990).

12) H. Morita, S. Eguchi, S. Nakayama and M. Miyahara: Weed Research Jpn. 34, 41-42 (1989) (in Japanese).

13) K. Noda and K. Ibaragi: Weed Research Jpn. 4, 105-109 (1968) (in Japanese).

14) S. Kanematsu, M. Akiyama and M. Hiramatsu: Abstr. 39th Annu. Meeting Pestic. Sci. Soc. Jpn. 75 (2014) (in Japanese).

15) C. J. Peter and J. B. Weber: Weed Sci. 33, 874-881 (1985).

16) K. Hoshikawa: Bot. Gaz. 130, 192-203 (1969).

17) M. Suzuki and T. Suto: Weed Research Jpn. 20, 114-117 (1975) (in Japanese). 